\title{
Multiple Means of Engagement Strategies for Maximising the Learning of Mathematics in Pandemic-regulated Classrooms
}

\author{
Matshidiso M. Moleko \\ University of the Free State, South Africa \\ https://orcid.org/0000-0002-1437-7218
}

\begin{abstract}
Many learners find mathematics learning challenging. In response to that actuality, this paper highlights mathematics teachers' experiences of, and insights into how they adopted and implemented the principle of "Multiple Means of Engagement" (MME) to maximise learning in pandemic-regulated classrooms (in the context of the study, characterised by alternative weeks of attendance, social distancing and wearing of masks). The MME principle is one of the three universal design for learning (UDL) key principles, which guides on how diverse groups of learners can be effectively catered for. The empirical processes, premised on a phenomenological case study, commenced with focus group discussions with 8 high school mathematics teachers from a previously disadvantaged area, who have prior-training in MME. A free attitude interview (FAI) technique was used, to afford the teachers the opportunity to share their insights into the application of MME in their pandemic-regulated classrooms. The content analysis of the teachers' reflections revealed the following aspects: clear instructions, step-by-step guides, checklists to enhance self-regulation, varying demand and resources to meet challenges, fostering collaboration, providing corrective feedback to sustain effort and persistence, addressing mathematical vocabulary and using real-life situations to recruit interest. These strategies were found not only essential in maximising learning in mathematics under normal circumstances, but also indispensable during the prevailing conditions of the pandemic. The findings therefore suggest MME as a suitable mathematical approach during this Covid19 period.
\end{abstract}

Keywords: learner engagement; Mathematics teaching; maximising learning; multiple means of engagement

\section{Introduction}

The purpose of the study was to highlight mathematics teachers' experiences of and insights into how they implemented the multiple means of engagement (MME) principle to maximise learning in pandemic-regulated classrooms. MME 
is one of the key principles of the universal design for learning (UDL) teaching framework, which encompasses strategies to engage diverse groups of learners in meaningful activities meant to motivate them, address anxiety, and maximise learning (Dalton, 2017). Many learners find mathematics learning challenging and become demotivated, anxious, and disengaged in the classroom. With respect to this, Smith (2004) notes that most mathematics classrooms are occupied by learners with negative thoughts and feelings towards mathematics. These learners often develop anxiousness about mathematics that causes them to be less likely to continue working on mathematical problems, especially when they fail to understand these the first time (Smith, 2004). This makes the teaching of mathematics even more challenging, since teachers have to ensure that they not only teach mathematics effectively but at the same time also deal with issues pertaining to a lack of motivation, learners' negative thoughts and feelings towards mathematics, and learners' state of being disengaged. According to Filgona et al. (2020), learners who are unmotivated tend to be disengaged, which often leads to behaviour that makes the teaching of mathematics difficult. However, Gray and Madson (2007) and Hake (1998) maintain that mathematics teachers have a responsibility to ensure that learners are not disengaged in the classroom by using interactive approaches that have proven to be useful in terms of engaging learners and providing them with actual gain in learning.

Learner engagement is regarded as a way of addressing problems and emotional dispositions such as demotivation, anxiousness and disengagement that learners often experience in various school subjects and specifically in mathematics (Padgett et al. 2019). In short, learner engagement is seen as a potential solution for addressing these emotional dispositions in an endeavour to encourage learners to accomplish learning tasks, persist in the midst of challenge, develop academic satisfaction, and remain engaged with the given tasks (Halverson and \& Graham, 2019).

Williams and Williams (2011) view engaging learners in learning as an important ingredient for success and a key to academic motivation and persistence. Kuh et al. (2011) hold the act of engaging learners in the learning process in high esteem and regard it as crucial in terms of promoting learner success. According to Yengin et al. (2010), engaging learners in the learning process is a strategy that puts learners at the centre of their learning and inspires them to participate and take on an active role in the learning process.

Learner engagement is further regarded as an essential precursor for maximising learning (Zyngier, 2007). Engaging learners in the learning process provides many benefits, including increased "attention and focus, motivation to practise higherlevel critical thinking skills and promoting meaningful learning experiences" (Park, 2003). Three domains of engagement have been identified through the literature, namely "cognitive, emotional, and behavioural engagement" (Fredricks et al. 2004). Behavioural engagement is often observed through actions such as learners paying attention and cooperating and participating in class activities (Hughes, 2012), while cognitive engagement is exhibited through selfefficacy, motivation, focus, and psychological effort from an individual (Duchesne 
\& Ratelle, 2010). "Emotional engagement" is noticeable through a sense of community and belonging, support in the classroom, identifying with school, and one's feelings towards school and learning (Fredricks et al. 2004). Research shows that learners who are highly engaged often demonstrate active involvement in learning and usually have high academic achievements (Appleton et al., 2008; Fredricks et al., 2004; Leonard, 2008; Smith et al., 2010; Sirin \& Rogers-Sirin, 2005). Moreover, they demonstrate a positive attitude and behaviour towards their schoolwork (Smith et al., 2010).

Although learner engagement positively influences learning, many teachers seem to have difficulty in engaging learners, and this often results in low learner participation in class activities, demotivation, and disengagement (Parsons et al., 2014). Teachers' challenges with regard to engaging learners were recently exacerbated by the Covid-19 pandemic that forced schools to close (during the lockdown) and then apply an alternating attendance system for learners to be able to maintain social distancing inside the classroom. All of these changes had a significant impact on the teaching of mathematics and raised the levels of demotivation and learner disengagement in the classroom. The fact that teachers had not been trained to teach under the prevailing conditions and lack knowledge of inclusive teaching strategies (Bansilal \& Ubah, 2019) makes it even more challenging for mathematics teachers to teach and effectively engage learners under these conditions. Furthermore, the nature of teaching mathematics that necessitates learner engagement, which is currently impeded by the restrictions of the pandemic, makes it difficult for teachers to teach and create a teaching and learning space that is conducive for diverse learner population (Klein, 2000). Balwant (2018) stresses that disengagement in the classroom is a serious challenge that should be addressed in order to maximise learning. In line with Balwant's statement, Thoonen et al. (2011) suggest the need for improving teaching practices and, more so, ways to engage learners in order to maximise learning. The fact that learner engagement serves as a precursor for maximising learning (Zyngier, 2007) raises, even more, the need for teachers to consider strategies to meaningfully engage learners in order to maximise learning. Taking all of this into account, the current study sought to highlight mathematics teachers' experiences of and insights into how they implemented the MME to maximise learning during the Covid-19 period (in their pandemic-regulated classrooms).

MME is one of the UDL principles that provides guidelines for enhancing motivation and learner engagement in order to maximise learning (Burgstahler, 2008). It addresses issues of learner variability (e.g. different learning styles and preferences) and provides flexible choices for engagement in the learning process (Dalton, 2017). Since learners have different learning preferences and needs (Boothe et al., 2018), they also differ in the manner in which they have to be engaged. MME thus requires mathematics teachers to use varied engagement strategies applicable to all types of learners, regardless of their background to ensure that learners do not undergo the psychological and emotional distress (Pokhrel, \& Chhetri, 2021). 


\subsection{Significance of the study}

The MME principle serves as a guide for assisting teachers in terms of applying strategies to engage diverse groups of learners in meaningful activities meant to motivate them, address anxiety, and maximise their learning. Learners differ distinctly in terms of how they should be engaged and motivated to learn. For instance, some learners engage spontaneously and through innovation, while others frequently disengage and thus prefer a "stringent routine". Some learners prefer to solve mathematical problems individually, while others prefer to embark on collaborative problem solving activities. This means that there is no single "means of engagement that will suit all learners in all contexts"; consequently, there is a need for teachers to "provide multiple options for engagement". MME thus provides a comprehensive guide for engaging learners by varying "options for self-regulation, options for sustaining effort and persistence, and options for recruiting interest". The study thus has at least two theoretical inferences: firstly, the findings contribute to the advancement of literature on learner engagement practices to be used in mathematics classrooms; and secondly, the study serves as a guide for informing inclusive planning of mathematics teaching.

\subsection{Study Context}

The Thabo Mofutsanyane district is in the central part of South Africa in the Free State province. The district has low socio-economic status and is densely populated, with about 647 schools. Poor performance, especially in mathematics, is often reported in this district, and many teachers there are in need of training in more effective methods of learning and teaching. Three years prior to the outbreak of the Covid-19 pandemic, the researcher was a teaching and learning coordinator at the local university and was involved in the in-service training of mathematics teachers. She introduced them to the concepts of UDL and MME, which captured their interest and led to the implementation of an action research project with the purpose to empower them with teaching strategies aimed at improving their teaching practices in order to maximise learning in mathematics. The action research project ran for two years (2017-2018) through four phases, namely planning, action, observation, and reflection. Through this, the participants were empowered with knowledge and skills on how to implement UDL principles in their mathematics classrooms by the end of the project in 2018. When the pandemic started, the researcher became interested in how these mathematics teachers would adopt the MME principle during one year of pandemic regulations that had a large impact on the learning environment, such as the lockdown period (no school attendance) and social distancing, which led to a system of alternating school weeks for learners. The interest was sparked by the fact that the school in which the research was conducted was of lower socioeconomic (deprived of the luxury of online facilities).

The school in which the study was conducted had approximately 1600 learners who attended school on a fortnightly basis (i.e., two weeks per month). The teachers engaged in focus group discussions in which they shared their experiences of and insights into how they used the MME principle to engage 
learners in learning, thereby "providing options for self-regulation, for sustaining effort and persistence, and for recruiting interest".

The school in which the study was conducted, was in a developing environment wherein poverty levels were high, with poor infrastructure and lack of computers which meant that the online learning was not an option. Teachers therefore had to be creative in terms of thinking of ways in which they can support learning even when they were not physically present to teach learners. Their efforts were exemplary to others in similar environment and with a possibility of adaptation to online learning as well.

\subsection{Overview of the article}

The article commences with a brief overview of perspectives from the literature on the learner engagement theory and MME as a UDL principle. The methodology section provides detail on the design and execution of the study. In the discussion of the findings, the experiences and insights of the participants are shared to indicate how they adopted the MME principle during one year of Covid19 regulations, especially the lockdown (no school attendance) and social distancing that led to a system of alternating school weeks, which had a significant impact on the learning environment. All these views lead to a conclusion on the use of MME in the learning of mathematics by diverse groups of learners in challenging learning environments.

\section{Literature review on Multiple Means of Engagement}

The UDL is a teaching framework that comprises of three principles, namely "multiple means of representation, multiple means of action and expression, and MME" (Center for Applied Specialised Technology, 2011). It is an approach to teaching that requires teachers to rethink their teaching strategies in order to address the needs of all learners. It affords learners opportunities to demonstrate what they know in several ways. The UDL refers to "an approach to teaching that involves the proactive design and use of inclusive teaching strategies that benefit a broad range of learners, including those with disabilities (Scott et al., 2002, p.1)". Although UDL comprises of the three principles as already mentioned, this article focuses only on one of these principles, namely; MME. The MME principle is expedited through the application of numerous and flexible methods of engagement of students' learning that are incorporated into teaching to support affective learning (Boothe et al., 2018; Dalton, 2017; Evmenova, 2018). It requires teachers to use diverse strategies that allow learners to be engaged and motivated to learn (Dalton et al., 2012).

According to cognitive science, the affective network is part of the brain that is linked to MME, which addresses the "why" of learning (Rose \& Meyer, 2002). Affective networks help regulate emotional involvement with learning such as learners' motivation and their ability to focus on and remain engaged with a task (Darling-Hammond et al., 2020). MME, which is linked to affective networks, requires teachers to be reflective about their teaching practices in order to devise flexible engagement strategies to enhance mathematics learning. 
It should be noted though that the MME principle does not only address the issue of why learners engage but also why they engage in the manner in which they do. For this reason, Hartnett (2020) stresses the need to consider it in teaching and learning contexts. Courey et al. (2013) also recommend the use of MME, as it enables teachers to recognise that no single option of engagement works for all learners and provides a comprehensive guide in terms of how teachers should provide learners with a range of engaging learning materials to maximise their learning and engage them in meaningful mathematics learning. Capp (2020) notes that MME is vital to help stimulate learners' interests and increase their motivation to learn and, accordingly, recommends teachers to consider it.

When teachers apply the MME principle, they are often advised to look into finding ways to link material to learners' lives, interests, and experiences by giving them choices (Dalton, 2017). This principle guides engagement by providing three types of options, namely; "options for self-regulation, for sustaining efforts and persistence, and for recruiting interest" (Capp, 2020; Center for Applied Specialised Technology, 2014). In this study, teachers reflected on how they used this principle to maximise mathematics learning. The study therefore highlights the teachers' experiences of and insights into how they provided these three options. Table 1 reflects the MME principle and the guidelines it consists of. These are the guidelines that guided or informed the study.

Table 1: Multiple means of engagement principle (Center for Applied Specialised Technology, 2014)

\begin{tabular}{|l|l|}
\hline Provide multiple means of engagement \\
\hline Provide options for self-regulation \\
+ Promote expectations and beliefs that \\
optimise motivation \\
+ Facilitate personal coping skills and strategies \\
+ Develop self-assessment and reflection \\
\hline $\begin{array}{l}\text { Provide options for sustaining effort } \\
\text { and persistence }\end{array}$ \\
$+\quad$ Heighten salience of goals and \\
objectives \\
+ Vary demands and resources to \\
optimise challenge \\
$+\quad$ Foster collaboration and a sense of \\
community \\
+ Increase mastery-orientated feedback \\
Provide options for recruiting interest \\
+ Optimise individual choice and autonomy \\
+ Optimise relevance, value, and authenticity \\
+ Minimise threats and distractions \\
\hline
\end{tabular}

\section{Learner Engagement Theory}

The learner engagement theory was adopted as the lens underpinning the study. Engagement refers to an individual's active participation and involvement in a particular activity, where motivation expresses impetus behind the activity (Appleton et al., 2006). Sinatra et al. (2015) postulate that the "concept of engagement" can be explored from different levels in the learning process. The 
first level is "micro-level engagement", which they define as a learner's state of "engagement in a moment, task, or learning activity". This is the level that is typically found in a class with a time constraint in the order of minutes to hours. The second level is "macro-level engagement" which characterises engagement across time (e.g., days and weeks), contexts (e.g., classwork, homework, and groupwork) and activities associated with the learning tasks that take place before and after learning events. According to Csikszentmihalyi (1997), the highest degree of micro-level engagement is represented by the flow concept, which is experienced when interaction with the learning task results in the learner being "in a state of effortless attention, arising through an interaction between positive affect and high attention" (De Manzano et al., 2010, p. 301). According to Engeser (2012), flow is observable when learners become "totally absorbed in" and focus on the given tasks. The improved "state of flow" takes place under three main conditions, namely; clearly defined task goals provided to the learners, prompt constructive feedback provided to the learners regarding their performance and progress made, and the learners' current skill levels being "matched to the challenge" they are faced with (Engeser \& Rheinberg, 2008). The learner engagement theory was deemed suitable for the study because it highlights different types of engagement, explains what engagement should look like, and outlines what makes it successful.

\section{Research Design and Methodology}

In this phenomenological case study, eight teachers (with teaching experience ranging from 8 to 18 years) of one high school in the Thabo Mofutsanyane district were purposively selected to participate in the research. Of the eight teachers who participated in the study, five were males and three were females. The age of the teachers ranged between 36 to 52 years. The school in which the research was conducted is one of the biggest high schools in the district, with an enrolment of approximately 1600 learners. The school was selected because the mathematics teachers in this school had previously undergone UDL training and, therefore, were familiar with all of its principles, including MME. These teachers were chosen because of their lengthy experience in teaching mathematics and their knowledge of the application of UDL principles in the classroom.

A series of six recorded focus group discussions, each session lasting for two hours, were conducted to generate data. As the teachers had previously undergone UDL training and had implemented the principles in their classes prior to the outbreak of the pandemic, the researcher became interested in finding out how they were using these principles (especially the MME principle) given the pandemic that had forced schools to observe the rules of the national disaster (wearing masks, social distancing, etc.).

Focus group discussions were conducted with the mathematics teachers so that they could provide first-hand information on how they had implemented the MME principle to maximise learning. The themes that were used were informed by the guidelines of MME as shown in Table 1. The first theme was based on the teachers' implementation of MME to "provide options for self-regulation"; the second theme was based on the teachers' implementation of MME to "provide 
options for sustaining effort and persistence"; and the third theme was based on the teachers' implementation of MME to "provide options for recruiting interest". The subthemes and categories were also informed by the MME guidelines as shown in Table 1. The themes and subthemes were used to understand how the teachers had adopted MME to maximise mathematics learning.

The qualitative content analysis techniques were used to analyse the data; they were partly directed and partly inductive. The techniques involved numerous steps for analysing data, beginning with the reading of the data texts, placing different labels on the texts to differentiate it (open-coding), and clustering the emerging concepts into bigger clusters (categories). The bigger clusters were further grouped into themes that came out from the data (Hsieh \& Shannon, 2005). The analysis of data in this study was directed because the general themes were determined a priori. Since the study sought to explore a phenomenon using a few participants in their school setting, the findings of this study cannot be generalised. However, in a context similar to that of this study, these results could apply. Furthermore, the findings of this study may contribute to the body of knowledge by illuminating some ways in which MME can be implemented to effectively engage learners and maximise learning.

The free attitude interview (FAI) technique was used for data collection during the focus group discussions. In line with FAI, the open-ended questions that were posed during the focus group discussion (based on how the teachers had implemented the MME principle by providing "options for self-regulation, for sustaining effort and persistence, and for recruiting interest" to maximise learning) made it possible for the participants to engage in lengthy discussions leading to the generation of rich data. In order to eliminate researcher bias, member checking was conducted to ensure that the data were analysed and the findings interpreted in a manner that correctly captured and portrayed the participants' explanations, ideas, and opinions.

The University of the Free State issued ethical clearance to conduct the research. The Free State Department of Education and the principal of the school where the study was conducted were approached in order to ask for their permission to conduct the study and they gave approval. The participants (teachers) in the research signed consent forms. Their right to confidentiality was emphasised, and anonymity was guaranteed. The participants were requested to participate on a voluntary basis, and they were informed that they would not be penalised should they decide not to proceed with participation at any stage of the research project.

\section{Findings and Discussion}

The following sections highlight the mathematics teachers' experiences of and insights into how they adopted the MME principle and applied it to provide the "options for self-regulation, options for sustaining effort and persistence, and options for recruiting interest". 


\subsection{Provide Options for Self-regulation}

Self-regulation is of extreme importance, especially in the pandemic context in which learners were given tasks to perform individually. This necessitated the teachers to develop self-regulation strategies to enable learners to learn independently and to maximise learning. During a focus group discussion, the teachers reflected on how they had implemented the MME principle to provide options for self-regulation. They highlighted some of the strategies they had employed to "promote expectations and beliefs that optimise motivation" (Center for Applied Specialised Technology, 2011). They reflected as follows:

It is important to give mathematical tasks with clear instructions on what [is] to be done. Learners usually respond better when they know what they are expected to do. They also respond better when they are given the opportunities to tackle tasks in their own ways. (Teacher 3)

It also helps to let learners know what you want from them ... what is it that you want them to do ... what you expect of them to do with respect to tasks that you give them. (Teacher 4 )

I found it useful to give learners problems which they understand. They become motivated when they work with such problems. (Teacher 2)

The above extracts indicate the significance of making learners understand expectations in order to successfully engage them and maximise their learning. According to Teacher 3, teachers can do so by providing learners with clear instructions on what is expected from them so that they know how to approach the given tasks. According to both Teachers 3 and 4, learners respond better when they understand the tasks they are given and know what is expected from them. According to Teacher 2, it is vital to give learners mathematical problems that they understand, as this will motivate them to attempt to solve these tasks or problems. What also seems to be important to do as part of engaging learners and maximising their learning is to give them opportunities to solve problems using their own approaches. Such opportunities will make learners feel in charge and responsible for their own learning processes and thus raise their motivation to engage in the given tasks. The form of teaching that is espoused from the extracts in which expectations are promoted is regarded as a "high impact practice", which Ambrose et al. (2010) deem significant in terms of motivating learners to learn so that they can make the progress necessary to contribute towards their metacognitive gains. Teaching that promotes high expectations and beliefs not only improves learning but also elevates motivation, inculcates a sense of selfefficacy in learners, and results in the higher levels of engagement necessary for meaningful mathematics learning experiences and maximising learning.

As learners were given tasks to work on individually whilst at home during the lockdown, teachers had to use strategies that helped facilitate the learners' coping skills. The teachers reflected as follows:

What I tried to do during lockdown was to give my learners detailed examples and step-by-step guidelines for solving problems so that they can [sic] do the problems on their own wherever they were. (Teacher 4) 
I found giving tasks together with the checklists helpful because the learners are able to check how far they are with the task and also what is still outstanding. This also eliminates distractions they might come across and ease the anxiety that comes with engaging them with the task while working alone. (Teacher 1)

Giving them different ways to solve the mathematical problems helps, especially when I give similar tasks because the learners were able to apply the methods that worked for them and not rely on the ones that I introduced them to. (Teacher 5)

The extracts above indicate that engagement is not only a "classroom business" but an important practice that should also be implemented when learners are working on their own outside the mathematics classroom. The pandemic had thus forced teachers to use strategies that would help learners engage with the learning tasks while working individually without their teacher's physical presence. According to Teacher 4, learners can be engaged outside the classroom with the tasks given to them by providing them with detailed, explicit examples, serving as a guide on how to solve the problems, and step-by-step guidelines on how to solve mathematical problems before they have to solve similar problems independently. According to Lipscomb et al. (2004), a step-by-step guide serves as an important practice and a useful scaffold for supporting learning by helping to bridge the task demand in light of the learners' current level, thus enabling learners to be more successful than they would have been otherwise. Step-by-step task-orientated scaffolding also provides learners with ample support and guidance necessary to manage the main areas of difficulty when they are working independently (Smirnova, 2016). According to Teacher 1, checklists are also useful when learners work independently, as these help learners to monitor their own work and to establish where they are with the given tasks by identifying the completed and outstanding parts of the tasks. Checklists therefore serve as an adaptive strategy for helping learners to monitor, manage, and direct their emotional responses to external events, while also helping to reduce taskirrelevant distracters. Hyppönen, Hirsto \& Sointu (2019) note that learners who monitor themselves and also have the ability to self-regulate their "learning processes are more likely to perform well in their academic tasks". Moreover, Teacher 5 alluded that exposing learners to different ways of solving mathematical problems not only optimises learning but can also serve as an opportunity for teachers to assist learners in coping with the demands of the mathematical content. Introducing different methods of solving mathematical problems provides learners with an opportunity to select and use simple methods for them, which, in turn, makes it possible for learners to cope with the demands of the given tasks.

Developing the self-assessment and reflection strategy was also highlighted as a good strategy for self-regulation. The teachers reflected as follows:

Although we are able to monitor the learners' progress when giving them problems to solve in class, we still have to make sure that we empower our learners to be able to monitor their own progress when they are working on their own ... Eeeerrrrr, like during the lockdown. (Teacher 7) 
Bearing in mind that our learners differ in so many ways, I think we need to give clear guidelines to all of them, especially those who cannot be able [sic] to do this on their own. (Teacher 8)

I assisted my learners to do self-assessments and reflections, and I realised that that helped them realise areas where they were struggling as well as realise the progress they were making, and that was really motivating for them. (Teacher 6)

Monitoring is an important teaching and learning practice that teachers have to inculcate in learners so that they are able to monitor their progress. This was emphasised by Teacher 7 , who pointed out that teachers had the responsibility to enable learners to monitor their own progress. This means that teachers have to develop self-assessment strategies and explicitly teach and guide learners on how to do self-assessment. By doing so, the teachers will develop a better capacity for self-regulation. According to Bercher (2012), self-assessment and reflection are important because they enable learners to monitor not only their progress but also their emotions and reactivity sensibly. In accordance with Teacher 7, Teacher 8 added that learners differed in many ways and, on the basis of this, teachers had to provide a great deal of explicit instruction and guidelines for learners for them to learn how to successfully self-assess. The need for self-assessment and reflection was further stressed by Teacher 6, who encouraged teachers to help learners self-assess and reflect because the mere recognition of one's own progress towards greater independence could be highly motivating.

\subsection{Provide Options for Sustaining Effort and Persistence}

The discussion on how teachers implemented the MME principle revealed the need to offer alternatives for sustaining effort and persistence as another important strategy to engage learners and maximise learning. The teachers pointed out the significance of reminding learners about the lesson outcome expected to be achieved and how to achieve it. They reflected as follows:

I think we need to keep on reminding learners of the lesson outcome they are expected to achieve. When learners are given a task to do, they must be given timeframes to complete it and in-between be reminded of what they have to do to achieve the lesson outcome. (Teacher 3)

I often try to show various ways in which the goal can be achieved. (Teacher 1)

... the same way I do in class under normal circumstance[s] to encourage learners and motivate them to learn, I found that working for me, especially when giving them meaningful feedback to enable them to correct their mistakes and address misconceptions. (Teacher 5)

According to the extracts above, one way of sustaining effort and persistence when engaging learners, as highlighted by Teacher 3 , is by regularly reminding learners about the intended lesson outcome to be achieved regarding the given mathematical tasks. The timeframe for completing a task must be communicated, 
and teachers should be there to remind the learners about the lesson outcomes to be achieved and guide them so that the outcome can eventually be achieved. Such support is required to help sustain the effort and concentration of the learners in the face of distracters. Teacher 1 explained that the lesson outcome (i.e., intended goal) to be achieved should be displayed or demonstrated in multiple ways; hence the statement "I often try to show various ways in which the goal can be achieved". What Teacher 1 pointed out is important in order to cater for a diverse learner population. The practice of making a goal clear to the learners, in an endeavour to maximise learning, is advocated by Anderson and Stritch (2016), who avow that even if the goal may be difficult to achieve, when learners know it and are guided well on how to achieve it, they will pursue it. Hatip (2020) also espouses the notion of making a goal clearer so to maximise learning. Being guided on how to achieve the goal thus helps in terms of raising learners' motivation levels and inspires them to make an effort and persist in engaging in the given mathematical tasks, even in the face of challenges. According to Teacher 5, another way to sustain effort and persistence, especially in the time of the pandemic when learners are working independently, is to continually motivate and encourage the learners by providing them with immediate corrective feedback that will enable them to correct their mistakes and address misconceptions. Febrianto et al. (2020) also stress the significance of motivating learners when they are working independently particularly during the pandemic when teachers are not present. In engaging learners, teachers should keep in mind the fact that learners differ in terms of how they learn and their levels of understanding content. This implies that learners should be engaged in different ways and be given tasks that match their learning abilities and different levels of understanding. Consequently, teachers should vary the demand and resources to meet challenges when engaging learners in mathematical activities. This point was raised by Teachers 2 and 3, who narrated as follows:

We teach learners who learn differently, and therefore we need to vary the resources and also give tasks that learners will be able to tackle. (Teacher 2)

Knowing my learners helped me a lot because I was able to give them tasks that match their abilities. (Teacher 3 )

The practice of varying demand and resources to meet challenges when engaging learners is supported by the Center for Applied Specialised Technology (2011), which asserts that no single means of engagement is optimal for all learners in all contexts. According to Teacher 3, knowing the types of learners in her class was helpful in terms of devising activities that matched the abilities of her learners. Matching abilities with task demands thus helps to sustain motivation for learners to remain engaged with activities.

Fostering collaboration and a sense of community was also highlighted as a useful strategy for engaging learners and maximising learning (Mishra et al.,2020). Although during the lockdown, the teachers were not able to implement the strategy, they did manage to implement it shortly after the lockdown, during the period of alternating groups of learners coming to school every week. The teachers commented as follows: 
Although during [the] lockdown I could not be able [sic] to create groups for learners to work individually, I managed, though, to create the [sic] small groups during the period of alternating groups of learners that came to school after [the] lockdown. Creating such small groups in class was helpful. It gave learners opportunities to work together and learn from each other, although I had to ensure that they observe the social distancing rule and also wear masks during their interaction in class. (Teacher 6)

I formed the groups in such a way that learners were able to work well together so that they can benefit from each other. (Teacher 4)

I found it helpful to change the members of the groups from time to time. (Teacher 7)

Fostering collaboration among learners was not possible during the lockdown period; however, when the learners went back to school the teachers managed to get them to work in small, intimate groups while observing the rules of the pandemic. The teachers deemed the practice of fostering collaboration among the learners important as part of engaging learners and maximising their learning. According to Teacher 6 , fostering collaboration can be done by creating small, intimate groups. The teacher regarded group work as an important practice that should be implemented to afford learners opportunities to work cooperatively and learn from one another. Teacher 4 pointed out that the groups of learners should be carefully formed so that they could derive maximum benefit by learning from one another. Teacher 7 added that members of the groups should be changed from time. Changing the members of groups frequently allows flexibility and exposes learners to diverse ideas from time to time, which is vital for maximising learning. The practice of peer cooperation is highly espoused in teaching and learning contexts and is a practice that is highly recommended in the $21^{\text {st }}$ century. According to Poellhuber et al. (2008), peer collaboration helps to "create a sense of community" that is much needed to sustain learner motivation and persistence and support learners' commitment to studying and remaining engaged. McKeen (2019) notes that flexible grouping enables better differentiation and manifold roles, while also providing opportunities for learners to work collaboratively. Flexible grouping also allows mathematics teachers to adapt their teaching and this enables learners to achieve the learning objectives.

The teachers also reflected on increasing mastery-orientated feedback as a key strategy in implementing the MME principle of "providing options for sustaining effort and persistence" (Center for Applied Specialised Technology, 2011). The teachers reflected as follows:

When I engage my learners, it really helped to give them assessments and provide feedback from time to time, especially feedback that is encouraging and helpful ... I think we must give them feedback that makes them realise their mistakes so that they can be able [sic] to correct the mistakes, and this needs to be done on time. (Teacher 8)

Sometimes when we give feedback, we tend to compare and create unhealthy competitions amongst the learners. Again, we give feedback 
that focuses only on the marks instead of addressing the errors which learners often commit. I think this is what we need to change if we want our learners to remain engaged. (Teacher $\mathbf{1})$

According to Teacher 8, one way in which teachers can provide masteryorientated feedback is by frequently giving assessment and feedback. The expression "feedback that is encouraging and helpful" refers to feedback that not only makes it possible for learners to realise their mistakes and what causes these mistakes but also indicates areas where they are doing well. This means that assessment should not only focus on weaknesses but also point out the strengths of the learners as part of motivating them. The practice of giving constructive and corrective feedback is crucial in terms of sustaining the learners' motivation and effort towards learning (Al-Hattami, 2019).

According to Teacher 1, ensuring that learners remain engaged requires teachers to give constructive and corrective feedback that is aimed at building the learners and not unfair feedback that focuses on comparing their strengths and weaknesses. The feedback should not focus only on the marks awarded to learners but also on worked-out problems. This should be done by paying attention to how the problems were solved (i.e., steps for solving the problems) in order to identify errors made so as to share them with the learners at a later stage in an endeavour to enlighten and correct them. This type of feedback is regarded as masteryorientated feedback because it serves to guide learners towards "mastery rather than a fixed notion of performance compliance" (Darling-Hammond et al., 2020). This type of feedback is vital for sustained engagement because it accentuates the importance of "process" over "product", thus encouraging learners to embrace the notion of focusing on the attainment of the lesson objectives and appreciating the progress they are making in terms of learning content rather than focusing on the marks. This approach to feedback is also vital in terms of nurturing "mastery orientation on the part of the learners" where they seek not only to advance their understanding of content, skills and learning strategies, but also to identify relevancy of the mathematical concepts which they are learning and "meaningfulness" in the task itself (Ames, 1992; Hattie \& Gan, 2011).

The suggestions made by the teachers necessitate teachers to carefully look into the feedback they provide to ensure that it inspires persistence in learners to be able to remain engage in problem solving.

\subsection{Provide Options for Recruiting Interest}

The pandemic has made learning difficult for most learners, as they had to struggle individually working on their tasks. The issue of working individually necessitated teachers to devise strategies for recruiting learners' interest so they could remain engaged and motivated to work on the given mathematical tasks. The teachers thus highlighted some strategies that they used to optimise individual choice and autonomy as a way of recruiting learners' interest and maximise learning. They narrated as follows:

One of the things that worked for me was to try to relate content and real life. Relating content to real life helps because it makes learners realise the importance of what they are learning. (Teacher 5) 
... just because we present content in a manner which other learners find easy to relate to, that should not make us assume that all learners prefer to be taught in that way. We need to vary the activities and present content in different interesting ways. Eeeehhhh ... we really need to come up with different strategies that will stimulate the learners' interest.

(Teacher 7)

Teacher 5 highlighted the usefulness of real-life situations when engaging learners ("because it makes learners realise the importance of what they are learning") as one way in which teachers could maximise learning, engage learners in meaningful learning, and also recruit their interest in learning mathematical concepts. According to the teacher, the relevance of the concepts taught in class and demonstrating this relevance through authentic, meaningful activities maximise learning. Moleko and Mosimege (2020) avow that teaching mathematics in context increases engagement. This form of teaching enables learners to apply the learnt concepts in real life, helps develop their new perceptions and skills to be able to use mathematical reasoning to problems, and enhances their capability to partake in the "economy of today and tomorrow" (Umugiraneza et al., 2017).

According to Teacher 7, teachers should not "assume that all learners will find the same mathematical activities or content equally relevant or valuable"; therefore, they should accordingly vary the activities or forms of content representations "in order to cater for the diverse learning preferences and styles of all the learners". Teachers should also invest time in devising various strategies that will assist in terms of stimulating learners' interest so they will remain engaged. However, it should be noted that teachers can only successfully do so if they know their learners. For instance, teachers can design visual activities for learners who best assimilate information when represented in visual formats and do the same with other groups of learners with different learning styles and preferences (auditory learners, tactile learners, etc.).

In order for effective learner engagement to be realised and for learning to be maximised, teachers have to ensure that they minimise threats and distractions that may impede learning (Center for Applied Specialised Technology, 2011). In line with this, the teachers commented as follows:

I have realised that one of the things that kill our learners, especially when we do not address it, is the mathematical vocabulary. It is difficult for learners to solve problems when they do not understand some of these words. For example, words such as "at least", "compound", etc. should be taught to learners so that they can know what they mean. (Teacher 2)

Our teaching should not create misunderstandings because this later makes it difficult for learners to solve problems on their own. For example, two raised to exponent three should be pronounced as such and not as two to power three. (Teacher 3 )

Teacher 2 highlighted the significance of addressing the insufficient knowledge of mathematical vocabulary in order to eliminate knowledge gaps that could hamper the learning process. According to the teacher, lacking an understanding 
of the mathematical vocabulary could be a potential threat that can impede mathematical problem solving. The teacher gave an example of terms such as "at least" and "compound", which are not only used within a mathematical context but also in other contexts. These are words that teachers should explain so that their meanings can be understood in context to avoid confusion (Moleko \& Mosimege, 2020).

Furthermore, Teacher 3 noted that teaching that causes misunderstanding should be avoided in order for learners to be engaged in meaningful mathematics learning. The example the teacher gave is that of "two raised to exponent three" and "two to power three". According to the teacher, these two expressions are often used interchangeably; yet they do not mean the same thing. For example, two raised to exponent three can be represented numerically as $2^{3}$ (where 2 is a base and 3 an exponent); and $2^{3}$ (a base together with an exponent) is called a "power", mathematically speaking. Consequently, failure on the part of teachers to mind how they teach these mathematical expressions in class may result in teaching that causes distractions, which could subsequently impede learning. The teaching of mathematics therefore requires teachers to avoid or eliminate elements of distractions at all times in order to maximise learning.

\section{Summary of examples of multiple means of engagement strategies to maximise learning of mathematics in pandemic-regulated classrooms 6.1 Offer the Alternatives for Self-regulation}

The findings of the study indicated that during the lockdown period learners worked on their own without the physical presence of the educators to guide them. This necessitated the clear expectations regarding the given mathematical tasks to be communicated so that learners could understand what is expected of them. The significance of giving learners the mathematical problems, which they possess knowledge of, was highlighted as a good strategy to motivate and ensure that they remain engaged. This therefore means that the teachers have to design mathematical examples that are clear to follow, and also provide the step-by-step guidelines in order to make it easy for learners to solve similar given problems independently. Lipscomb et al. (2004) regard the step-by-step guide as an important practice and a useful scaffold to support learning and help bridge the task demand in light of the learners' current level. When learners are expected to learn independently, it also helps to provide them with checklists so that they can be able to monitor their own progress. Inculcating the culture of self-monitoring and empowering learners with skills to monitor their own progress is a worthwhile practice that helps facilitate independent learning (Bellini \& Peters, 2008). Self-assessment and reflection were also found to be useful in terms of enabling learners to identify areas in which they were struggling with as well as those they were making good progress on. Bercher (2012) regards self-assessment and reflection practices worthwhile in terms of assisting learners not only to monitor their progress but also to monitor their emotions and reactivity sensibly. A blend of these strategies emerging from literature and empirical data thus point to self-regulation, which is constituted within the MME framework. Since learners "differ markedly in the ways in which they could be engaged", this necessitates teachers to vary the strategies and to offer alternatives for self-regulation. 


\subsection{Offer the Alternatives for Sustaining Effort and Persistence}

Many learners find mathematics challenging and often develop senses of helplessness and resentment towards the subject. These behavioural dispositions are often exhibited by learners in classrooms, in the presence of teachers who are there to guide them. Solving mathematical problems on their own (without the presence of the teachers) thus require teachers to use strategies that will help sustain effort and persistence. Although this may be difficult to achieve, findings of the study indicate several MME strategies that can be used to sustain effort and persistence. These strategies include; regularly reminding learners about the intended lesson outcomes which should be achieved, communicating the timeframes for completing the tasks and guiding the learners on how to achieve the learning goal. Anderson and Stritch (2016), maintain that the practice of guiding learners on how to achieve the learning goal is significant because even if the learning goal may be difficult to achieve, when learners know it and are guided well on how to achieve it, they will pursue it regardless. Providing instant corrective feedback is also vital in terms of enabling learners to realise their mistakes and misconceptions soon and to correct them. Giving tasks that match the learners' learning abilities and different levels of understanding is also important in terms of motivating learners when they are working independently. This therefore necessitates teachers to vary the demand and resources to meet challenges when engaging learners in mathematical activities. Fostering collaboration amongst the learners affords learners with opportunities to work together to learn from one another. However, the groups should be carefully formed so that learners could derive maximum benefit by learning from one another. Changing the members of groups frequently is also important as it allows flexibility and exposes learners to diverse ideas from time to time. Poellhuber et al. (2008) espouse the notion of peer collaboration since it helps to "create a sense of community that is much needed to sustain learner motivation and persistence and support learners" commitment to studying and remaining engaged. Flexibility grouping on the other hand enables better differentiation (McKeen, 2019) and also allows teachers to tailor mathematics instruction such that they meet the needs of diverse learners. The practice of providing the constructive and empowering corrective feedback is crucial in terms of sustain motivation and effort (Al-Hattami, 2019). This should be the type of feedback that not only focus on making learners aware of their mistakes but also shows areas in which they are doing well. A mixture of these strategies emerging from literature and empirical data thus point to the notion of sustaining effort and persistence which is also constituted within the MME framework. Since learners differ in terms of motivation levels, MME thus advocates the notion of offering varied strategies and alternatives for sustaining effort and persistence.

\subsection{Offer the Alternatives for Recruiting Interest}

Recruiting interest is important to ensure that learners remain focused on the given mathematical tasks. One way to recruit interest is through the use of reallife situations. Learners learn best when real life situations which they are familiar with are used and related to the content they are being taught. This form of teaching enables learners to apply the learnt concepts in real life, to "develop new perceptions and skills to apply mathematical reasoning to problems", and to 
enhance their "capacity to participate" in the economy of today and tomorrow (Umugiraneza et al., 2017). Since learners may not find "the same mathematical activities or content equally relevant or valuable"; it is therefore advisable for teachers to vary the activities or forms of content representations in order to cater for the diverse learning preferences and styles of all the learners. Lack of understanding the mathematical vocabulary should be addressed since it can be a potential threat that can impede mathematical problem solving. Teaching that causes misunderstanding and confusion should therefore be avoided in order for learners to be engaged in meaningful mathematics learning.

The findings of the study revealed two significant contributions (made by the study): firstly, the findings of the study contribute to the expansion of the teaching and learning theories in mathematics to promote; active learning, inclusivity and sustainability. Secondly, the study serves as a guide for promoting learner engagement by proposing a "new idea" of multiple means of engagement (MME) approach in mathematics, which should be regarded as an essential strategy to promote active learning.

The summary of the MME strategies highlighted above were deemed useful to provide all learners a better platform for overcoming their problems with mathematics and the challenges brought about by the pandemic regulations. It should be noted though that, different environments may require different combinations/combinations of the above strategies.

\section{Conclusion}

The study highlighted how mathematics teachers had adopted MME to maximise learning. It was revealed that "no single means of engagement will be ideal for all learners in all contexts"; therefore, it is essential for teachers to vary their teaching strategies to provide multiple options for engagement. The teachers in the study maximised mathematics learning by using MME guidelines, namely; "providing options for self-regulation, options for sustaining effort and persistence, and options for recruiting interest". Providing options for self-regulation in the study involved promoting high expectations for optimising learner motivation to engage with the given mathematical tasks, facilitating personal coping skills and strategies for learners to sustain engagement with the tasks even in the face of difficulties, and developing self-assessment strategies and teaching learners how to use them so they were able to monitor their progress. Providing "options for sustaining effort and persistence" required the teachers to indicate the learning goal to be achieved and guide their learners on how to achieve it, to foster peer collaboration among the learners so they could engage and learn from one another, and to increase mastery-orientated feedback by providing immediate feedback that was constructive and corrective. Providing "options for recruiting interest" required the teachers to reinforce relevance and value by using real-life examples so that learners could recognise the applicability of the concepts they were learning in reality and also by eliminating elements of threats and distractions that might hamper learning. The MME approach in mathematics was also found to be useful in terms of developing purposeful and motivated learners. One of the greatest lessons the study provided is that teachers are "a crucial part 
of curriculum implementation" and therefore they cannot detach themselves from the learning experiences of learners (Mapuya, 2021). Hence they have to strive to monitor, assess and engage learners even when learners are not in class due to Covid pandemic.

\section{Recommendations}

The findings of this study suggest the need for further research to be conducted on different topics in mathematics in order for teachers to maximise learning through MME. It should be noted that different mathematics topics necessitate different ways in which learners can be engaged in the learning processes. The MME principle will therefore serve as a guideline for engaging learners in meaningful mathematics learning as well as maximising the learning thereof. Also, MME will enable teachers to cater for and provide alternative ways in which to engage a broad range of learners in meaningful mathematics learning experiences.

Funding: This research is funded by the National Research Foundation (NRF)

Conflicts of Interest: The author declares no conflict of interest. The study was conducted primarily for scholarly purposes. The conceptualisation of the study and all the empirical processes were not influenced by own personal interest or anticipated gain.

\section{References}

Al-Hattami, A. A. (2019). The perception of students and faculty staff on the role of constructive feedback. International Journal of Instruction, 12(1), 885-894.

Ambrose, S. A., Bridges, M. W., DiPietro, M., Lovett, M. C., \& Norman, M. K. (2010). How learning works: Seven research-based principles for smart teaching. John Wiley \& Sons.

Ames, C. (1992). Classrooms: Goals, structures, and student motivation. Journal of Educational Psychology, 84(3), 261. https://psycnet.apa.org/doi/10.1037/00220663.84.3.261

Anderson, D. M., \& Stritch, J. M. (2016). Goal clarity, task significance, and performance: Evidence from a laboratory experiment. Journal of Public Administration Research and Theory, 26(2), 211-225. https://doi.org/10.1093/jopart/muv019

Appleton, J. J., Christenson, S. L., \& Furlong, M. J. (2008). Student engagement with school: Critical conceptual and methodological issues of the construct. Psychology in the Schools, 45(5), 369-386. https://doi.org/10.1002/pits.20303

Appleton, J. J., Christenson, S. L., Kim, D., \& Reschly, A. L. (2006). Measuring cognitive and psychological engagement: Validation of the Student Engagement Instrument. Journal of School Psychology, 44(5), 427-445. https://doi.org/10.1016/j.jsp.2006.04.002

Balwant, P. T. (2018). The meaning of student engagement and disengagement in the classroom context: Lessons from organisational behaviour. Journal of Further and Higher Education, 42(3), 389-401. https:/ / doi.org/10.1080/0309877X.2017.1281887

Bansilal, S., \& Ubah, I. (2019). The use of semiotic representations in reasoning about similar triangles in Euclidean geometry. Pythagoras, 40(1), 1-10. https:// doi.org/10.4102/pythagoras.v40i1.480

Bellini, S., \& Peters, J. K. (2008). Social skills training for youth with autism spectrum disorders. Child and adolescent psychiatric clinics of North America, 17(4), 857-873. https://doi.org/10.1016/j.chc.2008.06.008 
Bercher, D. A. (2012). Self-monitoring tools and student academic success: When perception matches reality. Journal of College Science Teaching, 41(5), 26-32.

Boothe, K. A., Lohmann, M. J., Donnell, K. A., \& Hall, D. D. (2018). Applying the principles of universal design for learning (UDL) in the college classroom. The Journal of Special Education Apprenticeship, 7(3), 1-13.

Burgstahler, S. (2008). Equal access: Universal design of instruction. DO-IT, University of Washington. edu/doit/Brochures/Academics/equal_access_udi.htm

Capp, M. J. (2020). Teacher confidence to implement the principles, guidelines, and checkpoints of universal design for learning. International Journal of Inclusive Education, 24(7), 706-720. https:/ / doi.org/10.1080/13603116.2018.1482014

Center for Applied Special Technology. (2014). UDL guidelines - Version 2.0: Principle III provide multiple means of engagement. http://www.udlcenter.org/aboutudl/udlguidelines/principle3

Center for Applied Specialised Technology [CAST]. (2011).Universal Design for Learning Guidelines version 2.0. Wakefield, MA: Author.

Courey, S. J., Tappe, P., Siker, J., \& LePage, P. (2013). Improved lesson planning with universal design for learning (UDL). Teacher Education and Special Education, 36(1), 7-27. https://doi.org/10.1177\%2F0888406412446178

Csikszentmihalyi, M. (1997). Flow and education. NAMTA Journal, 22(2), 2-35.

Dalton, E. M. (2017). Beyond universal design for learning: Guiding principles to reduce barriers to digital \& media literacy competence. Journal of Media Literacy Education, 9(2), 17-29. http://digitalcommons.uri.edu/jmle/

Dalton, E. M., Mckenzie, J. A., \& Kahonde, C. (2012). The implementation of inclusive education in South Africa: Reflections arising from a workshop for teachers and therapists to introduce universal design for learning. African Journal of Disability, 1(1), 1-7. https://doi.org/10.4102/ajod.v1i1.13.

Darling-Hammond, L., Flook, L., Cook-Harvey, C., Barron, B., \& Osher, D. (2020). Implications for educational practice of the science of learning and development. Applied Developmental Science, 24(2), 97-140. https://doi.org/10.1080/10888691.2018.1537791

De Manzano, Ö., Theorell, T., Harmat, L., \& Ullén, F. (2010). The psychophysiology of flow during piano playing. Emotion, 10(3), 301. DOI: 10.1037/a0018432

Duchesne, S., \& Ratelle, C. (2010). Parental behaviors and adolescents' achievement goals at the beginning of middle school: Emotional problems as potential mediators. Journal of Educational Psychology, 102(2), 497. DOI: 10.1037/a0019320

Engeser, S. E. (2012). Advances in flow research. Springer Science+ Business Media. https:// psycnet.apa.org/doi/10.1007/978-1-4614-2359-1

Engeser, S., \& Rheinberg, F. (2008). Flow, performance and moderators of challenge-skill balance. Motivation and Emotion, 32(3), 158-172. DOI 10.1007/s11031-008-9102-4

Evmenova, A. (2018). Preparing teachers to use universal design for learning to support diverse learners. Journal of Online Learning Research, 4(2), 147-171. https://www.learntechlib.org/p/181969/

Febrianto, P. T., Mas' udah, S., \& Megasari, L. A. (2020). Implementation of Online Learning during The Covid-19 Pandemic on Madura lsland, Indonesia. International Joumal of Learning, Teaching and Educational Research, 19(8), 233-254. https://doi.org/10.26803/ijlter.19.8.13

Filgona, J., Sakiyo, J., Gwany, D. M., \& Okoronka, A. U. (2020). Motivation in learning. Asian Journal of Education and Social Studies, 16-37. https://doi.org/10.9734/ajess/2020/v10i430273 
Fredricks, J. A., Blumenfeld, P. C., \& Paris, A. H. (2004). School engagement: Potential of the concept, state of the evidence. Review of Educational Research, 74(1), 59-109. https://doi.org/10.3102\%2F00346543074001059

Gray, T., \& Madson, L. (2007). Ten easy ways to engage your students. College Teaching, 55(2), 83-87. https://doi.org/10.3200/CTCH.55.2.83-87

Hake, R. R. (1998). Interactive engagement versus traditional methods: A six-thousandstudent survey of mechanics test data for introductory physics courses. American Journal of Physics, 66(1), 64-74. https:// doi.org/10.1119/1.18809

Halverson, L. R., \& Graham, C. R. (2019). Learner engagement in blended learning environments: A conceptual framework. Online Learning, 23(2), 145-178. https:// doi.org/10.24059 /olj.v23i2 .1481

Hartnett, M. (2020). Relationships between online motivation, participation, and achievement: More complex than you might think. Journal of Open, Flexible and $\begin{array}{lll}\text { Distance } \quad \text { Learning, 24(1), } & \text { 75-88. }\end{array}$ https://search.informit.org/doi/10.3316/informit.195515786038745

Hatip, A. (2020). The Transformation Of Learning During Covid-19 Pandemic Towards The New Normal Era. PROCEEDING UMSURABAYA.

Hattie, J., Gan, M., \& Brooks, C. (2011). Instruction based on feedback. Handbook of Research on Learning and Instruction, 249-271.

Hsieh, H. F., \& Shannon, S. E. (2005). Qualitative health research. Three approaches to qualitative content analysis. Qualitative Health Research, 15(9), 1277-1288. https://doi.org/10.1177/1049732305276687

Hughes, K. (2012). A behavioural understanding of privacy and its implications for privacy law. The Modern Law Review, 75(5), 806-836. https:// doi.org/10.1111/j.1468-2230.2012.00925.x

Hyppönen, L., Hirsto, L., \& Sointu, E. (2019). Perspectives on University Students' selfregulated learning, task-avoidance, time management and achievement in a flipped classroom context. International Journal of Learning, Teaching and Educational Research. https:// doi.org/10.26803/ijlter.18.13.5

Klein, M. (2000). How active involvement in learning mathematics can preclude meaningful engagement: Contributions from Foucault. Pedagogy, Culture $\mathcal{E}$ Society, 8(1), 69-83. https://doi.org/10.1080/14681360000200079

Kuh, G. D., Kinzie, J., Schuh, J. H., \& Whitt, E. J. (2011). Student success in college: Creating conditions that matter. John Wiley \& Sons.

Leonard, S. H. (2008). Measuring cognitive and psychological engagement in middle school students [Doctoral dissertation. University of South Dakota].

Lipscomb, L., Swanson, J., \& West, A. (2004). Scaffolding. Emerging perspectives on learning, teaching and technology. http:// projects.coe.uga.edu/epltt/index.php?title=Scaffolding.

Mapuya, M. (2021). First-Year Accounting Student Teachers' Constructivist Learning Experiences, The Lecturer's Role and Implications for Curriculum Implementation. International Journal of Learning, Teaching and Educational Research, 20(1), 103-119. https:// doi.org/10.26803/ijlter.20.1.6

McKeen, H. (2019). The impact of grade level flexible grouping on math achievement scores. Georgia Educational Researcher, 16(1), 48-62. https:// files.eric.ed.gov/fulltext/EJ1206047.pdf

Mishra, D. L., Gupta, D. T., \& Shree, D. A. (2020). Online Teaching-Learning in Higher Education during Lockdown Period of COVID-19 Pandemic. International Journal of Educational Research Open, August, 100012. https://doi.org/10.1016/j.ijedro.2020.100012 
Moleko, M. M., \& Mosimege, M. D. (2020). Teachers' and learners' experiences for guiding effective teaching and learning of mathematics word problems. Issues in Educational Research, 30(4), 1375-1394. ttps:// search.informit.org/doi/10.3316/informit.606279637425764

Padgett, J., Cristancho, S., Lingard, L., Cherry, R., \& Haji, F. (2019). Engagement: what is it good for? The role of learner engagement in healthcare simulation contexts. Advances in Health Sciences Education, 24(4), 811-825. https://doi.org/10.1007/s10459-018-9865-7

Park, C. (2003). Engaging students in the learning process: The learning journal. Journal of Geography in Higher Education, 27(2), 183-199. https://doi.org/10.1080/03098260305675

Parsons, S. A., Nuland, L. R., \& Parsons, A. W. (2014). The ABCs of student engagement. Phi Delta Kappan, 95(8), 23-27. https://doi.org/10.1177\%2F003172171409500806

Poellhuber, B., Chomienne, M., \& Karsenti, T. (2008). The effect of peer collaboration and collaborative learning on self-efficacy and persistence in a learner-paced continuous intake model. International Journal of E-Learning $\mathcal{E}$ Distance Education / Revue Internationale du e-Learning et la Formation à Distance, 22(3), 41-62.

Pokhrel, S., \& Chhetri, R. (2021). A literature review on impact of COVID-19 pandemic on teaching and learning. Higher Education for the Future, 8(1), 133-141. https:// doi.org/10.1177\%2F2347631120983481

Rose, D. H., \& Meyer, A. (2002). Teaching every student in the digital age: Universal design for learning. Association for Supervision and Curriculum Development.

Scott, S., McGuire, J. M., \& Embry, P. (2002). Universal design for instruction fact sheet. University of Connecticut, Center on Postsecondary Education and Disability. https://www.westga.edu/student-services/counseling/assetscounseling/docs/universal_design_fact_sheet.pdf

Sinatra, G. M., Heddy, B. C., \& Lombardi, D. (2015). The challenges of defining and measuring student engagement in science. Educational Psychologist, 50(1), 1-13. https://doi.org/10.1080/00461520.2014.1002924

Sirin, S. R., \& Rogers-Sirin, L. (2005). Components of school engagement among African American adolescents. Applied Developmental Science, 9(1), 5-13. https://doi.org/10.1207/s1532480xads0901_2

Smirnova, L. A. (2016). Scaffolding preparation for a reading exam. Journal of Teaching English for Specific and Academic Purposes, 4(2), 391-398.

Smith, D. C., Ito, A., Gruenewald, J., \& Yeh, H. L. (2010). Promoting school engagement: Attitudes toward school among American and Japanese youth. Journal of School Violence, 9(4), 392-406. https://doi.org/10.1080/15388220.2010.509308

Smith, M. R. (2004). Math anxiety: Causes, effects, and preventative measures [Senior honors thesis. Liberty University]. https://digitalcommons.liberty.edu/honors/255

Thoonen, E. E., Sleegers, P. J., Oort, F. J., Peetsma, T. T., \& Geijsel, F. P. (2011). How to improve teaching practices: The role of teacher motivation, organizational factors, and leadership practices. Educational Administration Quarterly, 47(3), 496-536. https://doi.org/10.1177\%2F0013161X11400185

Umugiraneza, O., Bansilal, S., \& North, D. (2017). Exploring teachers' practices in teaching mathematics and statistics in KwaZulu-Natal schools. South African Journal of Education, 37(2). https://doi.org/10.15700/saje.v37n2a1306

Williams, K. C., \& Williams, C. C. (2011). Five key ingredients for improving student motivation. Research in Higher Education Journal, 12, 1.

Yengin, İ., Karahoca, D., Karahoca, A., \& Yücel, A. (2010). Roles of teachers in e-learning: How to engage students \& how to get free e-learning and the future. Procedia- 
Social and Behavioral Sciences, 2(2), 5775-5787. https://doi.org/10.1016/j.sbspro.2010.03.942

Zyngier, D. (2008). (Re)conceptualising student engagement: Doing education not doing time. Teaching and Teacher Education, 24(7), 1765-1776. https://doi.org/10.1016/j.tate.2007.09.004 